\title{
Regulatory T cells decrease invariant natural killer $T$ cell-mediated pregnancy loss in mice
}

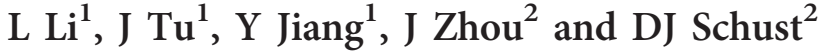

Pregnancy loss is the commonest complication of pregnancy. The causes of pregnancy loss are poorly understood. It has been reported that stimulation of invariant natural killer T (iNKT) cells using $\alpha$-galactosylceramide ( $\alpha$ GC) induces pregnancy loss in mice. Here we investigated the mechanisms, especially the role of regulatory $\mathrm{T}$ (Treg) cells, in iNKT cell-mediated pregnancy loss. We found that injection of $\alpha \mathrm{GC}$ rapidly induced fetal resorption, activated decidual iNKT cells, decreased the percentage of decidual Treg cells and their interleukin (IL)-10 and transforming growth factor (TGF)- $\beta$ production, and upregulated the levels of interferon (IFN)- $\gamma$, tumor necrosis factor- $\alpha$, IL-4, and IL-10 in serum. Adoptive transfer of iNKT cells from wild-type (WT) and IL-4 ${ }^{-I-}$ mice but not IFN- $\gamma^{-/-}$mice into $\alpha \mathrm{GC}$-treated iNKT cell-deficient $J \propto 18^{-/-}$mice restored $\alpha \mathrm{GC}$-induced pregnancy loss. Adoptive transfer of Treg cells downregulated $\alpha$-GC-induced pregnancy loss in WT mice. Finally, co-culture with aGC-stimulated decidual iNKT cells decreased the production of IL-10 and TGF- $\beta$ in decidual Treg cells and inhibited their suppressive activity. These findings suggest that activation of iNKT cells induces pregnancy loss in mice in an IFN- $\gamma$-dependent manner. In addition, inhibition of the function of decidual Treg cells has an important role in iNKT cell-mediated pregnancy loss.

\section{INTRODUCTION}

It is estimated that $50-70 \%$ of human conceptions fail, making pregnancy loss the commonest complication of pregnancy. ${ }^{1}$ Recurrent pregnancy loss, which can be defined as two or more consecutive pregnancy losses, is a devastating reproductive problem affecting $\sim 5 \%$ of couples attempting to conceive. ${ }^{2}$ Pregnancy loss has multiple etiologies. Besides chromosomal, anatomic, and endocrine factors, immunologic etiologies have long been proposed to be associated with this disease. ${ }^{3}$ A large body of evidence indicates that infections are associated with pregnancy loss. ${ }^{4}$ About $15 \%$ of early miscarriages and $66 \%$ of late miscarriages have been attributed to infections. ${ }^{5,6}$

Natural killer T (NKT) cells are a distinct T-cell subset that is present in human and mouse decidua., ${ }^{7,8}$ In contrast to conventional $\mathrm{T}$ (Tcon) cells that recognize peptide antigens, NKT cells respond to lipid in the context of the atypical major histocompatibility complex class I molecule CD1d. ${ }^{9}$ The bestcharacterized NKT cells are invariant NKT (iNKT) cells or type I NKT cells. iNKT cells express a semi-invariant T-cell receptor (TCR) composed of an invariant TCR $\alpha$ chain (V $\alpha 14-\mathrm{J} \alpha 18$ in mice and V $\alpha 24-\mathrm{J} \alpha 18$ in humans) that pairs with a limited selection of TCR $\beta$ chains. ${ }^{10}$ An important feature of iNKT cells is their ability to promptly produce a large number of cytokines, including interferon (IFN)- $\gamma$ and interleukin (IL)-4, in response to TCR engagement. ${ }^{11}$ This rapid induction of cytokine production contributes to the recruitment and activation of other immune cells, including Tcon cells, B cells, natural killer (NK) cells, dendritic cells, macrophages, neutrophils, and regulatory $\mathrm{T}$ (Treg) cells, thereby influencing a wide range of immunological responses. ${ }^{11}$

Treg cells are a special group of $\mathrm{CD} 4{ }^{+} \mathrm{T}$ cells that express the transcription factor forkhead box p3 (Foxp3) and suppress the activation, proliferation, and effector function of a variety of immune cells, including $\mathrm{CD} 4{ }^{+}$and $\mathrm{CD} 8{ }^{+} \mathrm{T}$ cells, B cells, NK cells, and antigen-presenting cells in vivo and in vitro. ${ }^{12}$ There are two main subsets of Treg cells. One is naturally occurring Treg cells that develop in the thymus; the other is induced Treg cells that are thought to arise in the periphery from naive $\mathrm{CD} 4{ }^{+}$ T cells. ${ }^{13}$ Treg cells are crucial in suppressing different types of inflammatory responses, including autoimmunity, allergy,

${ }^{1}$ Department of Obstetrics and Gynecology, Guangzhou First People's Hospital, Guangzhou Medical University, Guangzhou, China and ${ }^{2}$ Department of Obstetrics, Gynecology and Women's Health, University of Missouri School of Medicine, Columbia, Missouri, USA. Correspondence: L Li (doctorlipingli@foxmail.com) or DJ Schust (schustd@health.missouri.edu) 
acute and chronic infections, metabolic inflammation, tissue injury, and tumor immunity. ${ }^{14}$ Foxp3 is not only the marker of Treg cells but also critical for the differentiation and function of Treg cells. ${ }^{15}$ Dysfunction of Foxp3 results in congenital Treg cell deficiency and severe systemic immunopathology in both mice and humans, ${ }^{16,17}$ indicating that Treg cells are indispensable for immune homeostasis. In addition, Treg cells have been suggested to have an important role in maternal-fetal immune tolerance. ${ }^{13}$ Depletion of Treg cells before pairing results in infiltration of activated $\mathrm{T}$ effector cells, uterine inflammation and fibrosis, and impaired implantation in both allogeneic and syngeneic mating combinations, suggesting that Treg cells are necessary for successful implantation. ${ }^{18}$ Shima et al. ${ }^{19}$ have also reported that Treg cell depletion using an anti$\mathrm{CD} 25$ antibody $(\mathrm{Ab})$ in allogeneic and syngeneic pregnant mice induces implantation failure.

iNKT cells become activated in response to microbial lipid antigens, such as those derived from Plasmodium ${ }^{20}$ and Leishmania. ${ }^{21}$ Both pathogens are known to induce abortion at high frequency. In addition, iNKT cells are able to recognize exogenous lipid antigens, such as $\alpha$-galactosylceramide ( $\alpha G C)$. Upon recognizing the prototypical lipid $\alpha \mathrm{GC}$, iNKT cells are able to rapidly produce both $\mathrm{T}$ helper type 1 (Th1) and T helper type 2 (Th2) cytokines. ${ }^{22}$ As a strong agonist for iNKT cells, $\alpha \mathrm{GC}$ has been extensively used as a model antigen for iNKT cell studies, ${ }^{22}$ although several of its analogs have been synthesized to specifically induce either Th1 or Th2 responses. ${ }^{23,24}$ Activation of iNKT cells through intraperitoneal (IP) injection of $\alpha \mathrm{GC}$ induces rapid pregnancy loss in mice and has been proposed as a model of infection-mediated pregnancy loss. ${ }^{8}$ However, the mechanisms underlying iNKT cell-mediated pregnancy loss are poorly defined. In this article, we investigated these mechanisms. We demonstrate that activation of iNKT cells through IP injection of $\alpha \mathrm{GC}$ rapidly induces pregnancy loss in mice in an IFN- $\gamma$-dependent manner. In addition, inhibition of the function of decidual Treg cells has an important role in iNKT cell-mediated pregnancy loss.

\section{RESULTS}

\section{IP injection of $\alpha \mathrm{GC}$ rapidly activates decidual iNKT cells}

We first investigated whether IP injection of $\alpha \mathrm{GC}$ on day 9.5 of gestation could activate decidual iNKT cells as assessed by the percentage of iNKT cells in the decidua and the production of intracellular IFN- $\gamma$ and IL- 4 by decidual iNKT cells. IP injection of $\alpha \mathrm{GC}$ significantly increased the percentage of decidual iNKT cells $12 \mathrm{~h}$ after $\alpha \mathrm{GC}$ treatment $(P<0.01$; Figure 1a). Exposure to $\alpha \mathrm{GC}$ markedly upregulated the intracellular production of IFN $-\gamma$ $(P<0.01$; Figure 1b) and IL-4 $(P<0.01$; Figure 1c) by decidual iNKT cells. These findings suggest that IP injection of $\alpha \mathrm{GC}$ rapidly activates decidual iNKT cells.

\section{Induction of pregnancy loss by aGC requires iNKT cells}

To investigate the role of V $\alpha 14$ NKT cells in pregnancy loss, $\alpha \mathrm{GC}$ was injected IP into pregnant mice on day 9.5 of gestation. Seventy-two hours later, the number of total fetuses, viable fetuses, and embryo resorption rates (ERRs) were evaluated.
Conventional $\mathrm{T}$ cells do not express the invariant V $\alpha 14-\mathrm{J} \alpha 18$ antigen receptor, ${ }^{25}$ indicating their selective usage in V $\alpha 14$ NKT cells. Thus, disruption of the invariant V $\alpha 14-\mathrm{J} \alpha 18$ receptor results in the selective loss of iNKT cells, leaving other types of lymphocytes intact. ${ }^{8}$ In our study, the number of total fetuses, viable fetuses, ERR, and the appearance of the fetuses in vehicle-treated $J \propto 18^{-/-}$mice did not differ from vehicle-treated wild-type (WT) C57BL/6 mice (Figure 2a,b). Our data confirm that iNKT cell-deficient $J \alpha 18^{-/-}$mice that lack invariant $V \alpha 14-J \alpha 18$ TCR expression are fertile despite a loss of V $\alpha 14$ NKT cells. ${ }^{26}$ Treatment with $\alpha$ GC markedly decreased the number of viable fetuses and increased the ERR in WT mice $(P<0.01$ for both comparisons) (Figure 2a), suggesting an important involvement of iNKT cells in $\alpha \mathrm{GC}$-induced miscarriage. Administration of $\alpha \mathrm{GC}$ to pregnant C57BL/6 mice on day 9.5 of gestation rapidly induced pregnancy loss characterized by very small fetal size and hemorrhage by $72 \mathrm{~h}$ after $\alpha \mathrm{GC}$ injection (Figure 2b).

The number of total fetuses, viable fetuses, and the ERR in $\alpha \mathrm{GC}$-treated $J \alpha 18^{-/-}$mice was not different from vehicletreated WT or $J \alpha 18^{-/-}$mice (Figure 2a). Furthermore, the fetal appearance in $\alpha \mathrm{GC}$-injected $J \alpha 18^{-/-}$mice did not differ from vehicle-treated WT or $J \alpha 18^{-/-}$mice (Figure 2b). These results indicate that a deficiency in iNKT cells fails to induce pregnancy loss induced by $\alpha \mathrm{GC}$.

\section{Administration of $\alpha \mathrm{GC}$ upregulates serum cytokines in WT mice, but not in $J \propto 18^{-/-}$mice}

As the administration of $\alpha \mathrm{GC}$ promoted the secretion of cytokines at the maternal-fetal interface, we wondered whether treatment with $\alpha \mathrm{GC}$ could affect systemic cytokine production. As shown in Figure 2c, stimulation with $\alpha \mathrm{GC}$ notably increased not only the levels of the Th1 cytokines IFN- $\gamma$ and tumor necrosis factor (TNF) $-\alpha$ but also the production of the Th2 cytokines IL- 4 and IL-10 in the serum from WT mice $(P<0.01$, respectively). However, administration of $\alpha \mathrm{GC}$ had no effect on the production of those cytokines in the serum from $J \alpha 18^{-/-}$ mice. In addition, the production of those cytokines in the serum from vehicle-treated $J \alpha 18^{-/-}$mice did not differ from vehicle-treated WT mice. Our data demonstrate that deficiency of iNKT cells decreases $\alpha$ GC-mediated upregulation of serum cytokine production.

\section{Adoptive transfer of iNKT cells restores $\alpha \mathrm{GC}$-induced pregnancy loss in $J \propto 18^{-/-}$mice}

To further explore the role and mechanisms underlying the effects of iNKT cells in $\alpha \mathrm{GC}$-induced pregnancy loss, adoptive transfer of iNKT cells from pregnant WT, IFN- $\gamma^{-/}$and $I L-4^{-/-}$mice was performed. Adoptive transfer of WT and $I L-4^{-/-}$iNKT cells but not $I F N-\gamma^{-/-}$iNKT cells significantly reduced the number of viable fetuses of $\alpha$ GC-treated $J \alpha 18^{-/-}$mice $(P<0.01$ for both comparisons; Figure 3a). Moreover, adoptive transfer of iNKT cells from WT and $I L-4^{-\prime-}$ iNKT cells but not from $I F N-\gamma^{-/-}$ iNKT cells notably increased the ERR in $\alpha \mathrm{GC}$-stimulated $J \alpha 18^{-/-}$mice $(P<0.01$ for both comparisons; Figure 3a). These findings further confirm a role for iNKT cells in $\alpha$ GCinduced pregnancy loss and this effect is IFN- $\gamma$-dependent, but 
a

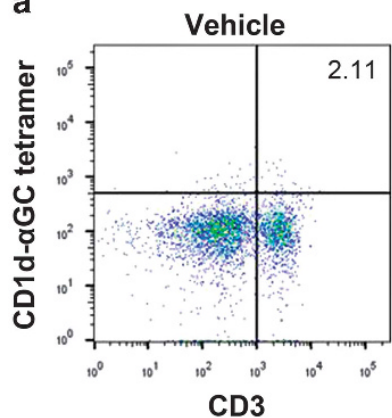

b

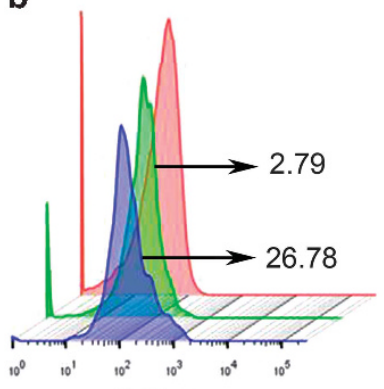

IFN-Y

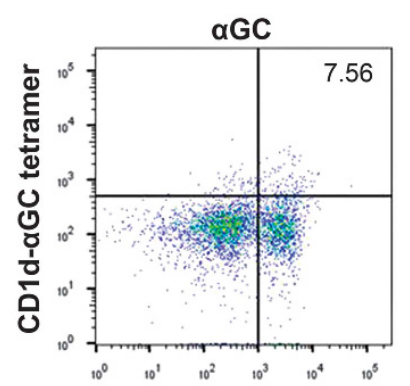

CD3

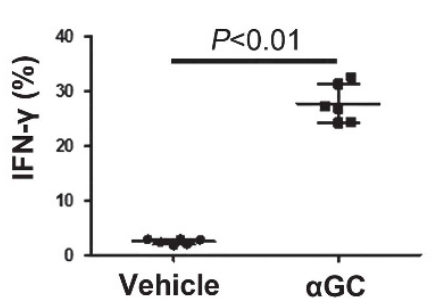

Figure 1 Intraperitoneal (IP) injection of $\alpha$-galactosylceramide $(\alpha \mathrm{GC})$ rapidly activates decidual invariant natural killer T (iNKT) cells. Pregnant C57BL/6 mice were injected IP with $\alpha \mathrm{GC}$ or vehicle on day 9.5 of gestation. After $12 \mathrm{~h}$, mice were killed and decidual mononuclear cells were isolated. (a) One representative experiment and a graphical summary of the percentages of decidual iNKT cells are shown. Numbers indicate the percentages of CD1d$\alpha \mathrm{GC}$ tetramer ${ }^{+} \mathrm{CD}^{+}$cells among CD3 ${ }^{+}$cells $(\%)(n=6)$. iNKT cell intracellular production of interferon (IFN)- $\gamma$ (b) and interleukin (IL)-4 (c) are presented. Red: isotype control. Green: vehicle control. Blue: $\alpha \mathrm{GC}$. Numbers indicate the percentages of IFN- $\gamma^{+}$cells or IL- $4^{+}$cells among iNKT cells (\%) $(n=6)$. not IL-4-dependent. As IFN- $\gamma$ signaling appeared to be essential in iNKT cell-induced pregnancy loss using a knockout model, we further investigated the role of IFN- $\gamma$ in fetal loss by using IP injection of recombinant mouse IFN- $\gamma$ into pregnant WT mice. As shown in Figure $\mathbf{3 b}$, administration of IFN $-\gamma$ significantly increased the ERR in WT mice $(P<0.01)$.

We also investigated the effects of adoptive transfer of iNKT cells on the levels of serum cytokines. Adoptive transfer of iNKT cells from WT and $I L-4^{-/-}$mice into $\alpha$ GC-exposed $J \alpha 18^{-/-}$mice significantly upregulated the production of the serum cytokines IFN- $\gamma$, TNF- $\alpha$, IL-4, and IL-10 $(P<0.01$, respectively; Figure 3c). However, adoptive transfer of iNKT cells from $I F N-\gamma^{-/-}$mice into $\alpha$ GC-exposed $J \alpha 18^{-/-}$mice did not affect the production of serum cytokines (Figure $3 \mathrm{c}$ ). These findings show that iNKT cells can promote systemic cytokine production and this effect requires IFN- $\gamma$ but not IL-4.

\section{Administration of $\alpha \mathrm{GC}$ decreases the percentage of decidual Treg cells and inhibits their suppressive activity} In order to explore the mechanisms underlying the effects of decidual Treg cells in iNKT cell-mediated pregnancy loss, we compared the percentages of decidual Treg cells, their secretion of IL-10 and transforming growth factor (TGF)- $\beta$, and their suppressive activities between $\alpha \mathrm{GC}$-pulsed and vehicle-treated WT mice. The percentage of Treg cells was calculated as the percentage of Foxp $3^{+}$cells among $\mathrm{CD} 4{ }^{+}$cells. Treatment with $\alpha \mathrm{GC}$ markedly decreased the frequency of decidual Treg cells

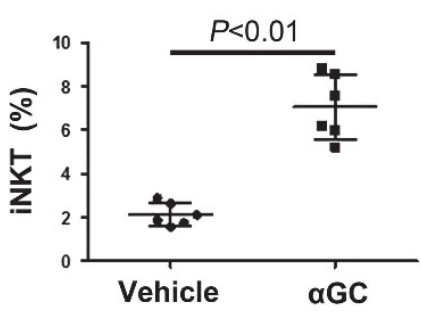

C
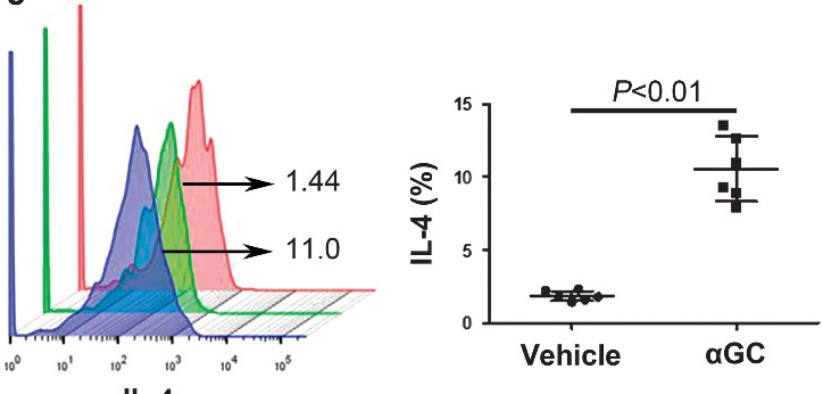

and reduced the levels of IL-10 and TGF- $\beta$ in decidual Treg cells $(P<0.01$, respectively; Figure $4 \mathbf{a}-\mathbf{c})$. In addition, administration of $\alpha \mathrm{GC}$ markedly downregulated the suppressive activity of decidual Treg cells, as demonstrated by an upregulation in carboxyfluorescein diacetate succinimidyl ester dilution in responder splenocytes $(P<0.01$; Figure $4 \mathbf{d})$ and increased levels of IFN- $\gamma$ (Figure 4e) and TNF- $\alpha$ (Figure 4f) in the supernatants of decidual CD $4{ }^{+} \mathrm{CD} 25^{-}$Tcon cells co-cultured with Treg cells. These findings suggest that administration of aGC decreases the frequency of decidual Treg cells and their regulatory function.

\section{Adoptive transfer of Treg cells inhibits $\alpha \mathrm{GC}$-induced pregnancy loss}

As Treg cells are crucial in maintaining maternal-fetal immune tolerance, we wondered whether Treg cells have a role in iNKT cell-mediated pregnancy loss as well. As shown in Figure 5, the number of total fetuses did not differ among vehicle-treated WT mice and $\alpha$ GC-treated WT mice with or without adoptive transfer of Treg cells. Nevertheless, the number of viable fetuses in $\alpha$ GC-treated WT mice with Treg cell adoptive transfer was markedly higher than $\alpha$ GC-treated WT mice without adoptive transfer of Treg cells $(P<0.01)$, but was still lower than vehicletreated control mice $(P<0.01)$. In addition, the ERR of $\alpha \mathrm{GC}$ treated WT mice with adoptive transfer of Treg cells was strikingly lower than that of $\alpha \mathrm{GC}$-treated WT mice without adoptive transfer of Treg cells $(P<0.01)$, but was still higher 

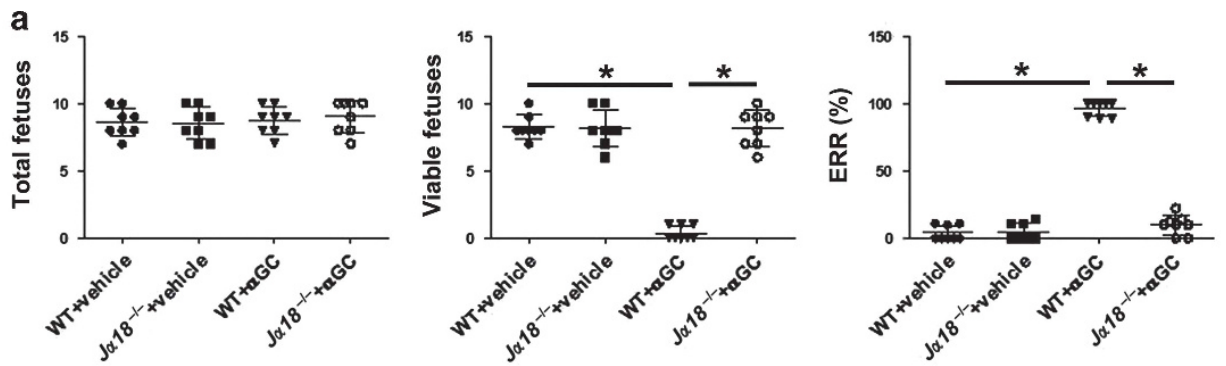

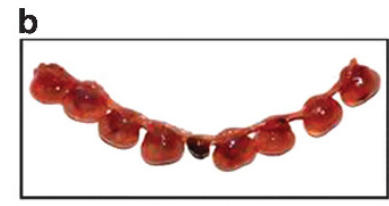

WT+vehicle

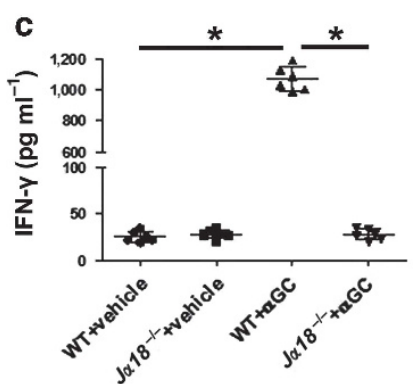

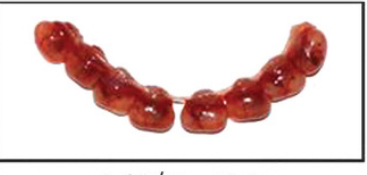

$J \alpha 18^{-1-}+$ vehicle

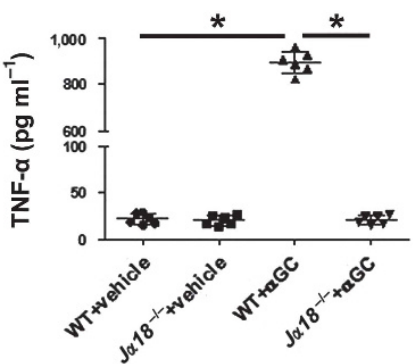

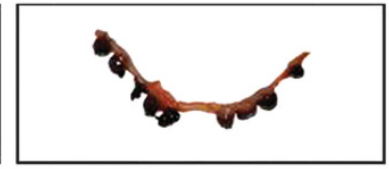

WT+aGC

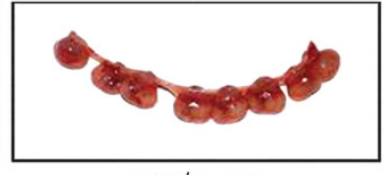

$J \alpha 18^{-1-}+\alpha G C$

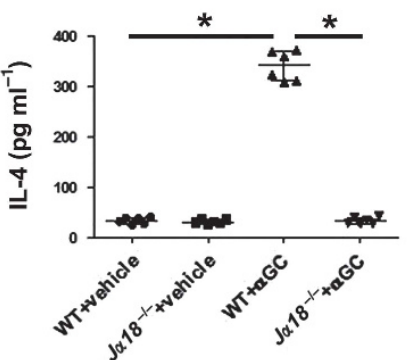

Figure 2 Comparison of fetal resorption and serum cytokines following in vivo $\alpha \mathrm{GC}$ stimulation. Pregnant wild-type (WT) or Ja 18 ${ }^{-/-}$mice were injected intraperitoneally with $\alpha$-galactosylceramide $(\alpha G C)$ or vehicle on day 9.5 of gestation. (a) The number of total fetuses, viable fetuses, and embryo resorption rates (ERRs) were calculated $72 \mathrm{~h}$ after $\alpha \mathrm{GC}$ treatment. Data are presented as mean \pm s.d. $(n=8)$. ${ }^{*} P<0.01$. (b) A representative macroscopic view of fetuses from WT or $J \alpha 18^{-1-}$ mice that received vehicle or $\alpha \mathrm{GC}$ is shown. (c) The production of serum interferon (IFN)- $\gamma$, tumor necrosis factor (TNF)- $\alpha$, interleukin (IL)-4 and IL-10 in each experimental group was analyzed $12 \mathrm{~h}$ after $\alpha \mathrm{GC}$ administration. Data are presented as mean $\pm \mathrm{s}$.d. of six independent experiments. ${ }^{*} P<0.01$.

than vehicle-treated control mice $(P<0.01)$. Our data suggest that iNKT cell-mediated pregnancy loss occurs at least partly through suppression of Treg cells.

\section{Co-culture with $\alpha$ GC-stimulated decidual iNKT cells inhibits the function of decidual Treg cells}

For in vitro co-culture experiments, Treg cells were isolated from the decidua of C57BL/6 mice. The purity of sorted $\mathrm{CD} 4{ }^{+} \mathrm{CD} 25^{+}$Treg cells was $\sim 95 \%$, as determined using flow cytometry (Figure 6a). Co-culture with $\alpha \mathrm{GC}$-pulsed decidual iNKT cells from WT and $I L-4^{-\prime-}$ mice significantly decreased the production of IL-10 and TGF- $\beta$ in decidual Treg cells compared with co-culture with vehicle-treated decidual iNKT cells from WT mice $(P<0.01$, respectively; Figure $\mathbf{6 b}, \mathbf{c})$. However, co-culture with $\alpha \mathrm{GC}$-stimulated decidual iNKT cells from $I F N-\gamma^{-/-}$mice did not change the production of IL-10 and TGF- $\beta$ in decidual Treg cells compared with co-culture with vehicle-treated decidual iNKT cells from WT mice (Figure 6b,c). In addition, co-culture of decidual Treg cells with $\alpha$ GC-pulsed decidual iNKT cells from WT and $I L-4^{-/-}$ mice but not $I F N-\gamma^{-1-}$ mice markedly decreased the levels of IL-10 and TGF- $\beta$ in the supernatants compared with co-culture with vehicle-treated decidual iNKT cells from WT mice $(P<0.01$, respectively; Figure 6d,e). Finally, co-culture with $\alpha$ GC-pulsed decidual iNKT cells from $I L-4^{-/-}$mice decreased the intracellular IL-10 and TGF- $\beta$ production by decidual Treg cells and IL-10 and TGF- $\beta$ levels in co-culture supernatants when compared with co-culture with vehicle-treated decidual iNKT cells from $I L-4^{-1-}$ mice $(P<0.01$, respectively; Figure $\mathbf{6 b}-\mathbf{e})$. However, co-culture with $\alpha \mathrm{GC}$-pulsed decidual iNKT cells from $I F N-\gamma^{-/-}$mice did not affect the intracellular IL-10 and TGF- $\beta$ production by decidual Treg cells and IL-10 and TGF- $\beta$ levels in co-culture supernatants when compared with co-culture with vehicle-treated decidual iNKT cells from $I F N-\gamma^{-/-}$mice (Figure $6 \mathbf{b}-\mathbf{e}$ ). Our findings demonstrate that activated decidual iNKT cells suppress the regulatory function of decidual Treg cells in vitro in an IFN- $\gamma$ dependent manner.

In support of our findings, pretreatment of $\alpha$-GC pulseddecidual iNKT cells with anti-IL- 4 Ab but not with anti-IFN- $\gamma \mathrm{Ab}$ significantly decreased the intracellular and extracellular production of IL-10 (Figure 7a,c) and TGF- $\beta$ (Figure 7b,d) by decidual Treg cells, further indicating that suppression of the function of decidual Treg cells by decidual iNKT cells requires IFN- $\gamma$.

\section{DISCUSSION}

The production of both Th1 (IFN- $\gamma$ ) and Th2 (IL-4) cytokines is a hallmark of iNKT cell activation. ${ }^{11}$ In the present study, we 

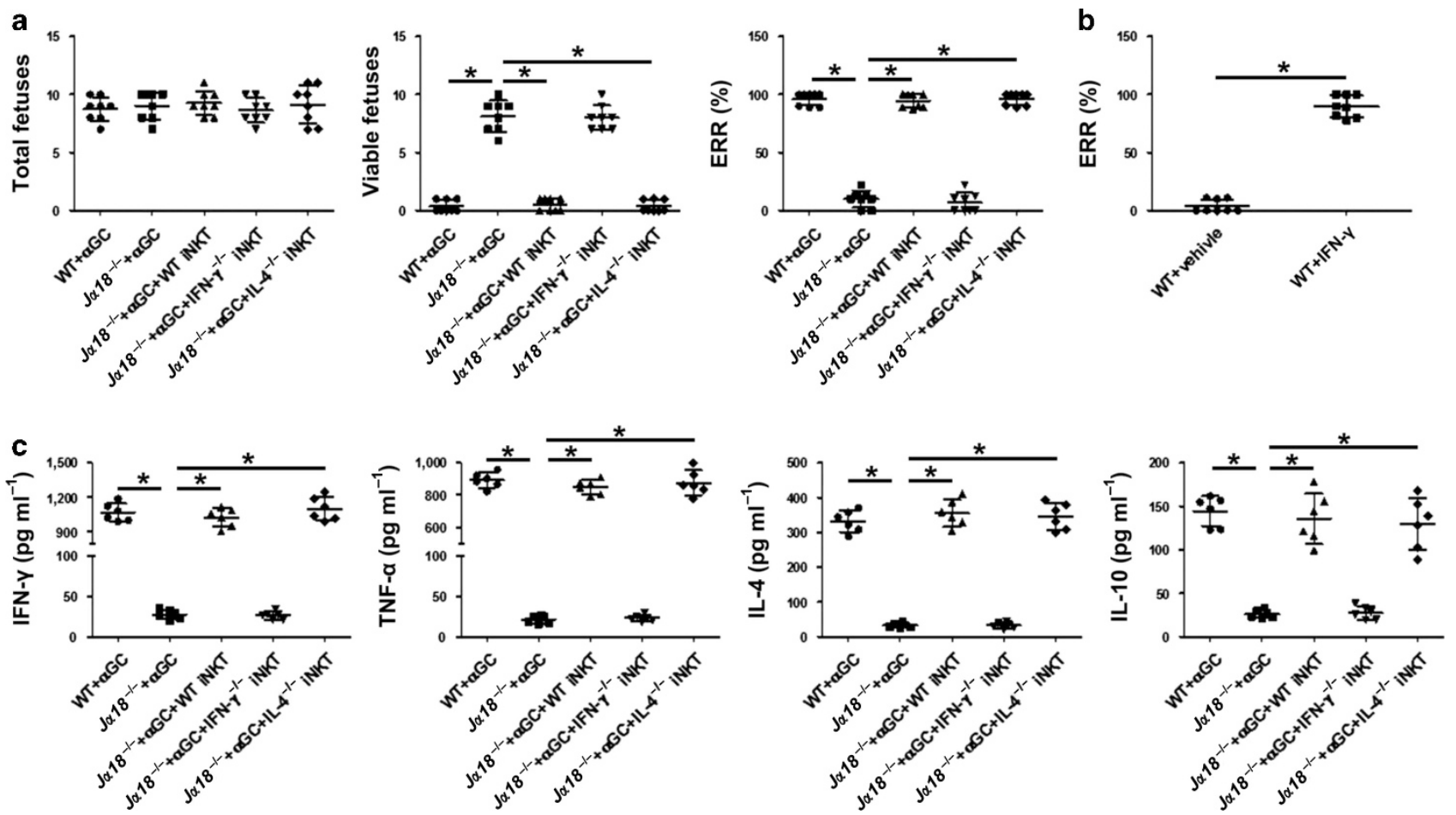

Figure 3 Adoptive transfer of invariant natural killer T (iNKT) cells restores $\alpha$-galactosylceramide $(\alpha \mathrm{GC})$-induced pregnancy loss in J $\alpha 18^{-/-}$mice. Pregnant wild-type (WT) and $J \propto 18^{-/-}$mice were injected intraperitoneally (IP) with $\alpha \mathrm{GC}$ or vehicle on day 9.5 of gestation. For iNKT cell reconstitution of $J \propto 18^{-/-}$mice, $5 \times 10^{5}$ purified iNKT cells from the spleens of WT, IFN- $\gamma^{-/-}$or $I L-4^{-\prime-}$ mice were injected into the tail veins of $J \alpha 18^{-/-}$mice $2 \mathrm{~h}$ before $\alpha \mathrm{GC}$ injection. The number of total fetuses, viable fetuses, and embryo resorption rates (ERRs) was measured $72 \mathrm{~h}$ after $\alpha \mathrm{GC}$ treatment $(n=8)(\mathbf{a})$, and the production of serum interferon (IFN)- $\gamma$, tumor necrosis factor (TNF)- $\alpha$, interleukin (IL)-4, and IL-10 in each experimental group was analyzed $12 \mathrm{~h}$ after $\alpha \mathrm{GC}$ injection $(n=6)$ (c). Some pregnant WT mice were injected IP with $10 \mu \mathrm{g} \mathrm{IFN}-\gamma$ or vehicle on day 9.5 of gestation, and ERRs were measured $72 \mathrm{~h}$ later $(n=8)(\mathbf{b})$. Data are presented as mean \pm s.d. ${ }^{*} P<0.01$.

showed that IP injection of $\alpha \mathrm{GC}$ into C57BL/6 mice promptly activated decidual iNKT cells as assessed by the elevated frequency of decidual iNKT cells and their intracellular production of IFN- $\gamma$ and IL-4. In addition, IP injection of $\alpha \mathrm{GC}$ not only increased IFN- $\gamma$ and IL- 4 at the maternal-fetal interface but also upregulated Th1 cytokines (IFN- $\gamma$ and TNF- $\alpha$ ) and Th2 cytokines (IL-4 and IL-10) in the serum, indicating that administration of $\alpha \mathrm{GC}$ via an intraperitoneal route induces both local and systemic inflammatory responses. The simultaneous increase in Th1 and Th2 cytokines suggests a non-biased cytokine secretion upon $\alpha \mathrm{GC}$ exposure, which is in agreement with the results of Boyson et al. ${ }^{27}$

In our study, treatment with $\alpha \mathrm{GC}$ decreased the number of viable fetuses and increased the ERR in WT mice but not in $J \alpha 18^{-1-}$ mice, suggesting that V $\alpha 14$ NKT cells are indispensable in $\alpha \mathrm{GC}$-induced pregnancy loss. Adoptive transfer of iNKT cells from WT mice into $\alpha$ GC-treated $J \alpha 18^{-/-}$mice restored $\alpha \mathrm{GC}$-mediated pregnancy loss, confirming the critical role played by iNKT cells in inflammation-mediated pregnancy loss. In addition, adoptive transfer of iNKT cells from $I L-4^{-/-}$ mice but not from $I F N-\gamma^{-/-}$mice promoted fetal loss in $\alpha \mathrm{GC}$ treated $J \alpha 18^{-1-}$ mice, demonstrating that iNKT cell-mediated pregnancy loss is IFN- $\gamma$-dependent, but not IL-4-dependent.

Similarly, administration of $\alpha \mathrm{GC}$ increased the levels of serum cytokines in WT mice but not in $J \alpha 18^{-/-}$mice.
Adoptive transfer of iNKT cells from WT mice or $I L-4^{-/-}$ mice but not from $I F N-\gamma^{-/-}$mice augmented serum cytokine production in $\alpha \mathrm{GC}$-treated $J \alpha 18^{-/-}$mice, suggesting that IFN- $\gamma$ is also necessary in iNKT cell-induced upregulation of serum cytokine production. Th1 cytokines, including IFN- $\gamma$ and TNF- $\alpha$, have been implicated in pregnancy loss. ${ }^{2,29} \mathrm{Th} 2$ cytokines, such as IL- 4 and IL-10, are pleiotropic cytokines that suppress pro-inflammatory responses. ${ }^{30}$ During pregnancy, Th2 cytokines increase markedly and promote fetal allograft tolerance by inhibiting Th1 responses. ${ }^{31}$ In the present study, although $\alpha \mathrm{GC}$ induced elevated production of Th1 and Th2 cytokines both at the maternal-fetal interface and in the serum, iNKT cell-mediated pregnancy loss required IFN- $\gamma$ but not IL-4. We hypothesize that the elevated Th2 cytokines may not be able to counteract the pro-inflammatory responses induced by increased Th1 cytokines. Indeed, IL- 4 and IL-10 have been shown to be non-essential for fetal survival as the litter size and development in IL-4 and IL-10 double-deficient mice are not different from those in WT mice. ${ }^{32}$

To our knowledge, reports on the interplay between iNKT cells and Treg cells at the maternal-fetal interface are scarce or absent. In the present study, we investigated the role of Treg cells in iNKT cell-mediated pregnancy loss. There are several lines of evidence supporting an essential role for Treg cells in the generation of maternal-fetal tolerance. First, Treg cells 
a
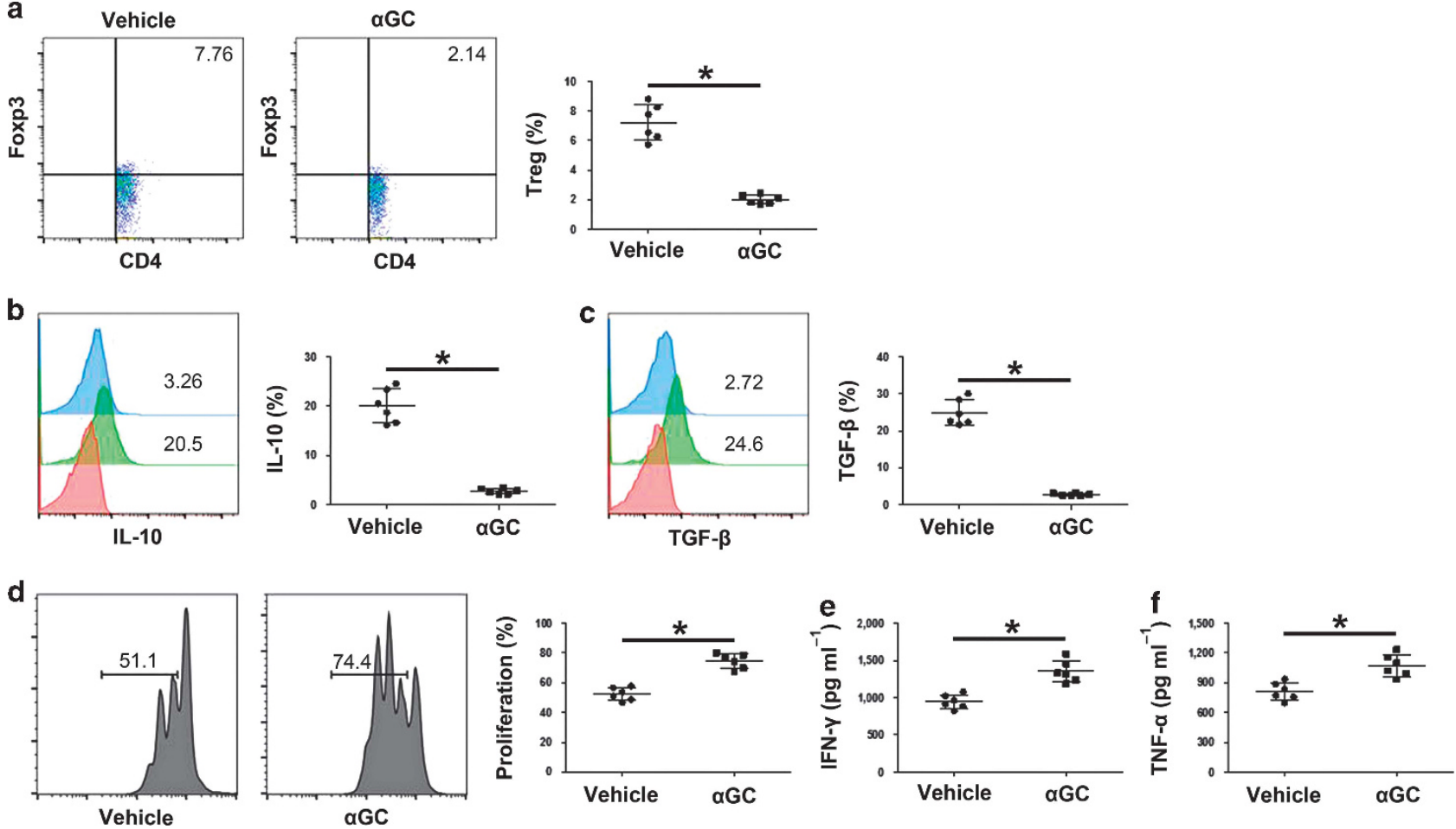

Figure 4 Administration of $\alpha$-galactosylceramide $(\alpha \mathrm{GC})$ decreases the percentages of decidual regulatory $\mathrm{T}$ (Treg) cells and inhibits their suppressive activity. Pregnant C57BL/ 6 were injected intraperitoneally with $\alpha \mathrm{GC}$ or vehicle on day 9.5 of gestation. After $12 \mathrm{~h}$, mice were killed and decidual Treg cells were isolated. (a) One representative experiment and a graphical summary of the percentages of decidual Treg cells are shown $(n=6)$. Numbers indicate the percentages of $\mathrm{Foxp}^{+} \mathrm{CD}^{+}$cells among CD4 ${ }^{+}$cells $(\%)$. Production of decidual Treg cell intracellular interleukin (IL)-10 (b) and transforming growth factor (TGF)- $\beta$ (c) are presented $(n=6)$. Red: isotype control. Green: vehicle control. Blue: $\alpha \mathrm{GC}$. Numbers indicate the percentages of IL-10 ${ }^{+}$ cells or TGF- $\beta^{+}$cells among Treg cells (\%). (d) One representative experiment and a graphical summary of the proliferation of responder splenocytes co-cultured with Treg cells are shown $(n=6)$. Numbers indicate the percentages of splenocytes undergoing at least one cellular division $(\%)$. Levels of IFN- $\gamma(\mathbf{e})$ and TNF- $\alpha(\mathbf{f})$ in the supernatants of conventional T cells co-cultured with Treg cells are presented $(n=6) .{ }^{*} P<0.01$.

increase significantly in the peripheral blood, decidual tissue, and lymph nodes draining the uterus during human and murine pregnancy. ${ }^{33,34}$ It has been suggested that Treg cells at the maternal-fetal interface are mainly of extra-thymic origin. ${ }^{35}$ However, recruitment of naturally occurring Treg cells cannot be ruled out as genetic depletion of induced Treg cells in mice lacking conserved non-coding sequence 1 enhancer element in the first intron of the Fxop3 gene, which is necessary for induced Treg cell generation, only results in mildly increased pregnancy loss. ${ }^{36}$ Second, spontaneous abortion cases are associated with a reduction in the number and suppressive capacity of Treg cells. ${ }^{37}$ Third, Ab-mediated depletion of $\mathrm{CD} 25^{+}$Treg cells induces implantation failure and fetal wastage in mice. ${ }^{19,38}$ Finally, adoptive transfer of pregnancy-induced Treg cells prevents fetal rejection in a murine abortion model. ${ }^{39}$

Activation of human naive $\mathrm{CD} 4^{+} \mathrm{T}$ cells induces Foxp3 expression, obscuring the identification of Foxp $3^{+} \mathrm{T}$ cells as pure Treg cells. ${ }^{40}$ In contrast, mouse naive $\mathrm{CD}^{+}{ }^{+} \mathrm{T}$ cells lack Foxp3 expression following activation. ${ }^{15}$ In our study, mouse Treg cells were therefore identified as $\mathrm{CD}^{+}{ }^{+} \mathrm{Foxp}^{+}$cells. Pathways activated by Treg cell-secreted IL-10 and TGF- $\beta$ are important in Treg cell suppressive activities. ${ }^{15}$ IL-10 decreases dendritic cell maturation ${ }^{41}$ and converts Tcon cells into IL-10-secreting $\mathrm{T}$ regulatory type 1 cells. ${ }^{42}$ TGF- $\beta$ induces Foxp3 expression in Tcon cells and promotes the conversion of peripheral $\mathrm{CD} 4{ }^{+} \mathrm{CD} 25^{-}$naive $\mathrm{T}$ cells into $\mathrm{CD} 4{ }^{+} \mathrm{CD} 25^{+}$Treg cells. ${ }^{43}$ We found that the activation of iNKT cells decreased the frequency of decidual Treg cells, Treg cell production of IL-10 and TGF- $\beta$, and Treg cell suppressive activity, indicating that iNKT cell-mediated suppression of decidual Treg cell function may have a role in $\alpha \mathrm{GC}$-induced inflammatory pregnancy loss.

As it is difficult to isolate Treg cells using intracellular Foxp3, and $\mathrm{CD} 4{ }^{+} \mathrm{Foxp}^{+}{ }^{+}$Treg cells in naive mice can be identified by the expression of CD25, ${ }^{44}$ we isolated mouse Treg cells using the cell surface markers CD4 and CD25. We found that adoptive transfer of Treg cells decreased fetal resorption in $\alpha$ GC-treated WT mice, further confirming a feedback pathway for Treg cells during the generation of maternal-fetal tolerance and $\alpha \mathrm{GC}$-induced pregnancy loss through suppression of Treg cells. Nevertheless, adoptive transfer of Treg cells did not restore the ERR to the extent seen in vehicle-treated control mice, demonstrating that other mechanisms may also be involved in iNKT cell-mediated fetal loss. Activated iNKT cells can activate other immune cells such as $\mathrm{T}$ cells, dendritic cells, and NK cells. ${ }^{11}$ These activated cells have been demonstrated to have a role in disrupting maternal-fetal tolerance. ${ }^{45,46}$ 

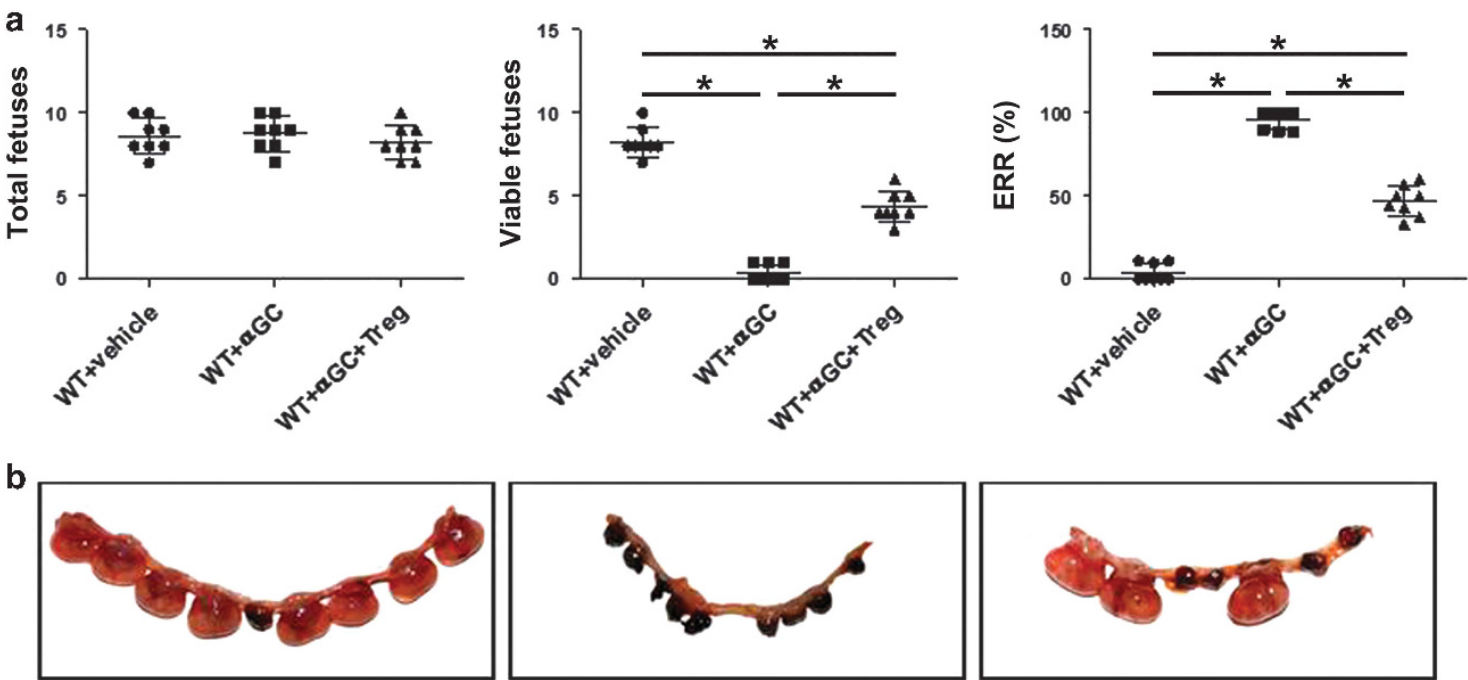

WT+vehicle

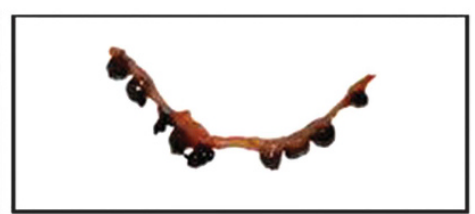

WT+aGC

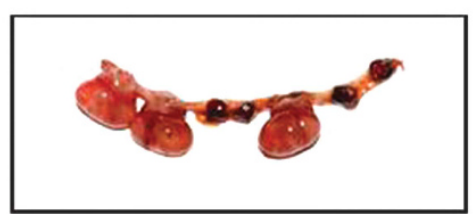

WT+aGC+Treg

Figure 5 Adoptive transfer of regulatory T (Treg) cells inhibits $\alpha$-galactosylceramide $(\alpha \mathrm{GC})$-induced pregnancy loss. Pregnant C57BL/6 mice were injected intraperitoneally with $\alpha \mathrm{GC}$ or vehicle on day 9.5 of gestation. For Treg cell reconstitution of wild-type (WT) mice, $5 \times 10^{5}$ purified Treg cells from the spleens of pregnant WT mice were injected into the tail veins of C57BL/6 mice $2 \mathrm{~h}$ before $\alpha \mathrm{GC}$ injection. After $72 \mathrm{~h}$, mice were killed and the number of total fetuses, viable fetuses, and embryo resorption rates (ERRs) (a) were assessed $(n=8)$. ${ }^{*} P<0.01$. (b) A representative macroscopic view of fetuses from WT mice that received vehicle, $\alpha \mathrm{GC}$, or $\alpha \mathrm{GC}$ plus adoptive transfer of Treg cells is shown.

Our in vitro co-culture experiments further indicate that activation of decidual iNKT cells inhibits the activation of decidual Treg cells as demonstrated by a decrease in intracellular production of IL-10 and TGF- $\beta$ by Treg cells and decreased secretion of IL-10 and TGF- $\beta$ into co-culture supernatants. In addition, $\alpha \mathrm{GC}$-stimulated iNKT cells from $I F N-\gamma^{-/-}$but not from $I L-4^{-/-}$mice had no effect on the activation of decidual Treg cells. Furthermore, pretreating $\alpha$ GC-pulsed iNKT cells with Ab against IFN- $\gamma$ but not against IL-4 did not affect the cytokine production by decidual Treg cells. Our data suggest that the iNKT cell-mediated decrease in the activation of decidual Treg cells in vitro is also IFN- $\gamma$ dependent.

In spite of their restricted TCR repertoire, iNKT cells can respond to a considerable variety of microbial pathogens ranging from viruses to parasites. In addition to directly recognizing various naturally occurring microbial lipids through the TCR, iNKT cells are also able to respond to a diverse array of microbes through inflammatory cytokines produced by antigen presenting cells upon Toll-like receptor stimulation. ${ }^{47}$ For instance, the Toll-like receptor 4 ligand Escherichia coli lipopolysaccharide, which is associated with inflammatory pregnancy loss, ${ }^{48}$ is able to indirectly activate iNKT cells through inflammatory cytokines IL-12 and IL-18. ${ }^{49}$ Both direct and indirect activation of iNKT cells enables them respond to a wide variety of microbes and contribute to inflammation-mediated pregnancy loss.

In summary, IP injection of $\alpha \mathrm{GC}$ rapidly induces pregnancy loss, and IFN- $\gamma$ is indispensable in iNKT cell-mediated pregnancy loss. In addition, this process is at least partly accomplished by restraining the suppressive function of Treg cells.

\section{METHODS}

Animals. Eight-week-old C57BL/6 mice were purchased from the Experimental Animal Center of Zhongshan University (Guangzhou, China). INF- $\gamma^{-/-}$and $I L-4^{-/-}$mice on a C57BL/6 background were purchased from The Jackson Laboratory (Bar Harbor, ME, USA). iNKT cell-deficient $J \alpha 18^{-/-}$mice on a C57BL/6 background were kindly provided by Taniguchi (RIKEN Institute, Yokohama, Japan). ${ }^{50}$ Mice were bred in the Laboratory Animal Center of Guangzhou Medical University (Guangzhou, China) in pathogen-free conditions. $J \alpha 18^{-/-}$mice were backcrossed at least 10 generations with $\mathrm{C} 57 \mathrm{BL} / 6$ mice. Syngeneic $\mathrm{C} 57 \mathrm{BL} / 6 \times \mathrm{C} 57 \mathrm{BL} / 6$ and $J \alpha 18^{-/-} \times J \alpha 18^{-/-}$ mating combinations were established. Each female mouse was cocaged with one male. The point at which a vaginal plug was detected was designated as day 0.5 of gestation. All experimental research on animals was approved by the Animal Care and Use Committee of Guangzhou Medical University.

$\alpha$ GC-induced abortion model. As described previously, ${ }^{27}$ on day 9.5 of gestation, pregnant $\mathrm{C} 57 \mathrm{BL} / 6$ and $J \alpha 18^{-/-}$mice were injected IP with $\alpha \mathrm{GC}\left(100 \mu \mathrm{g} \mathrm{kg}^{-1}\right.$ body weight) (Sigma, Saint Louis, MO, USA) in phosphate-buffered solution and $0.5 \%$ polysorbate- 20 or vehicle alone taking care not to enter the amniotic cavity. In selected experiments, C57BL/ 6 mice were injected IP with $10 \mu \mathrm{g}$ recombinant mouse IFN- $\gamma$ (Biolegend, San Diego, CA, USA). Animals were observed closely for any signs of morbidity (piloerection, decreased movement, and vaginal bleeding). Pregnant mice were killed after $72 \mathrm{~h}$ (day 12.5 of gestation). At this stage of gestation, feto-placental units undergoing resorption can be clearly distinguished from their viable counterparts on the basis of small size and the presence of extensive tissue wasting and hemorrhage. The number of total fetuses, viable fetuses, and resorbed embryos per mouse were counted. ERR was calculated as: $\operatorname{ERR}(\%)=$ number of resorbed embryos/number of total embryos $\times 100$. $^{27}$

Some mice were killed $12 \mathrm{~h}$ after $\alpha \mathrm{GC}$ injection. Serum was obtained from the tail vein and decidual mononuclear cells (MNCs) and Treg cells were isolated. The levels of IFN- $\gamma$, TNF- $\alpha$, IL- 4 , and IL-10 in the serum were assayed using enzyme-linked immunosorbent assay (ELISA). The percentages of iNKT cells and Treg cells, iNKT cell 
a

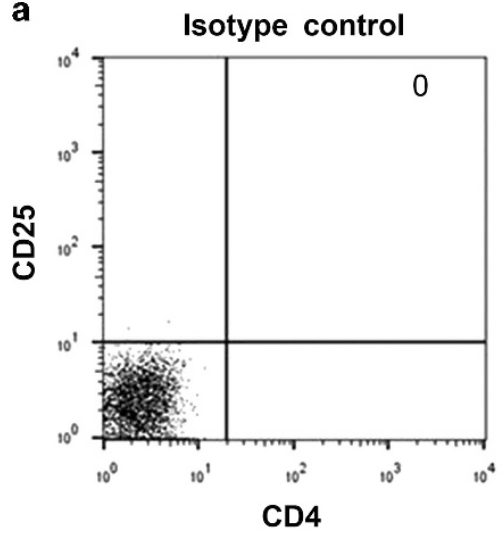

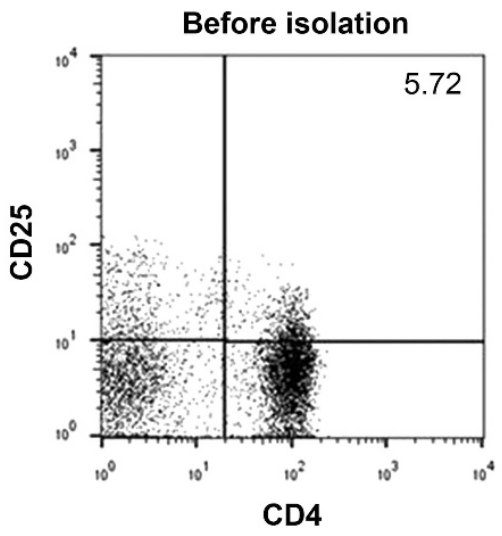

b

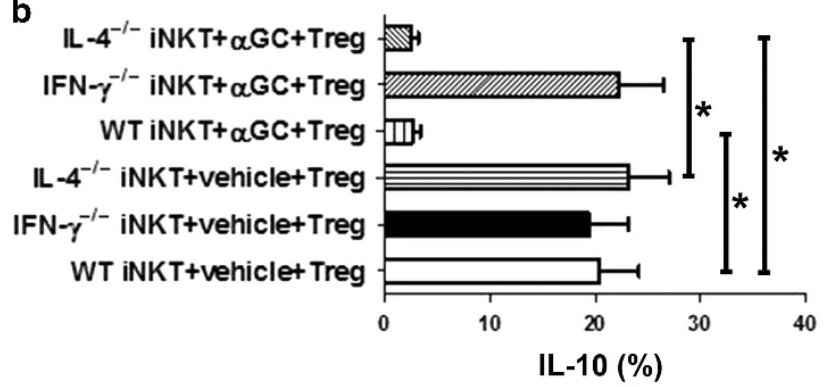

d

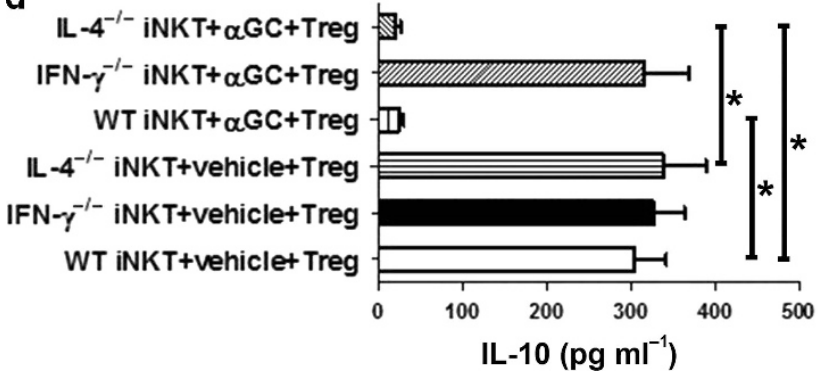

c

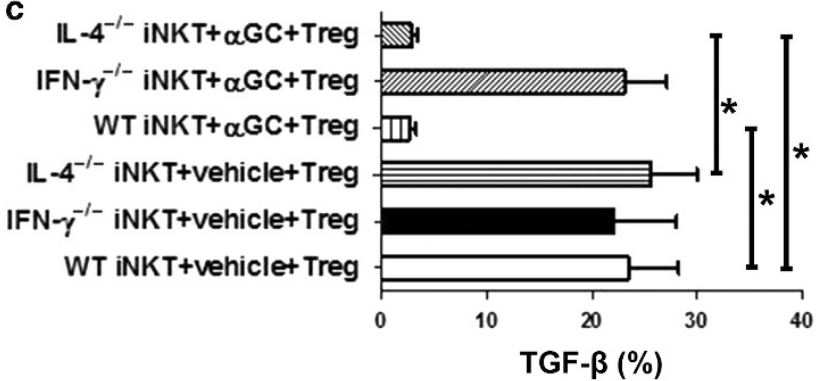

e

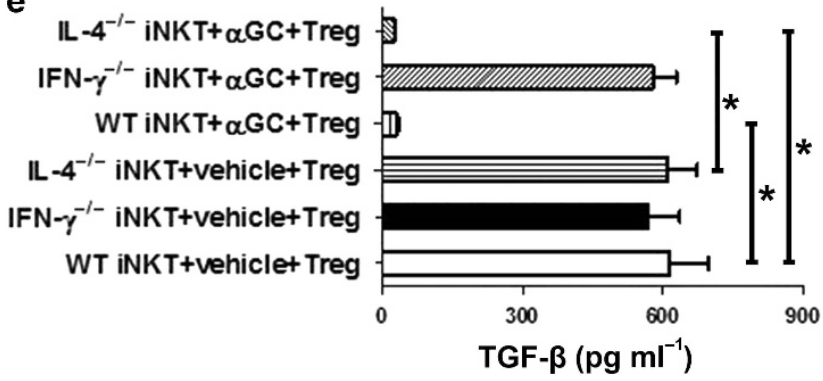

Figure 6 Co-culture with $\alpha$-galactosylceramide $(\alpha G C$ )-stimulated decidual invariant natural killer $T$ (iNKT) cells inhibits the function of decidual Treg cells. (a) One representative experiment depicting the purity of isolated decidual regulatory $\mathrm{T}$ (Treg) cells. Numbers indicate the percentages of $\mathrm{CD} 25^{+} \mathrm{CD} 4{ }^{+}$cells among $\mathrm{CD} 4{ }^{+}$cells $(\%)$. Decidual iNKT cells from wild-type (WT), IFN- ${ }^{-1-}$ and $/ L-4^{-1-}$ mice were incubated with $\alpha \mathrm{GC}$ or vehicle for $12 \mathrm{~h}$ and then extensively washed. A total of $5 \times 10^{4}$ decidual iNKT cells were co-cultured with $5 \times 10^{4}$ decidual Treg cells for $24 \mathrm{~h}$. The production of decidual Treg intracellular interleukin (IL)-10 (b) and transforming growth factor (TGF)- $\beta$ (c) and IL-10 and TGF- $\beta$ in culture supernatants (d and e, respectively) were measured. Data are presented as mean \pm s.d. of six independent experiments. ${ }^{*} P<0.01$.

intracellular IFN- $\gamma$ and IL-4 production, and Treg cell intracellular IL-10 and TGF- $\beta$ production were measured using flow cytometry. The suppressive activity of decidual Treg cells was analyzed (see below).

Adoptive transfer of decidual iNKT cells or Treg cells. As murine iNKT cells increase during the early and middle gestation, ${ }^{51}$ for iNKT cell reconstitution of $J \alpha 18^{-/-}$mice, $5 \times 10^{5}$ purified iNKT cells from the spleens of pregnant WT, IFN- $\gamma^{-/-}$, or $I L-4^{-/-}$mice on day 12.5 of gestation were injected into the tail veins of $J \alpha 18^{-/-}$mice $2 \mathrm{~h}$ before $\alpha \mathrm{GC}$ injection on day 9.5 of gestation. It has been reported that murine Treg cells increase during early pregnancy and peak during the midgestation. ${ }^{52}$ For Treg cell reconstitution of WT mice, $5 \times 10^{5}$ purified Treg cells from the spleens of pregnant WT mice on day 12.5 of gestation were injected into the tail veins of C57BL/6 mice $2 \mathrm{~h}$ before $\alpha \mathrm{GC}$ injection on day 9.5 of gestation. Mice were killed $72 \mathrm{~h}$ after $\alpha \mathrm{GC}$ injection and the number of total fetuses and viable embryos per mouse, and ERRs were calculated. Some mice were killed $12 \mathrm{~h}$ after $\alpha \mathrm{GC}$ injection. Serum was collected and analyzed for cytokine production.

Isolation of splenocytes. Spleens were mashed through a $40 \mu \mathrm{m}$ cell strainer (Thermo Fisher Scientific, Waltham, MA, USA) to obtain single-cell suspensions. Splenocytes were then enriched by lysing red cells using a red cell lysis buffer (Biolegend).

Isolation of decidual MNCs. The uterine horns of pregnant mice were opened longitudinally, and the entire placental and decidual units were separated individually from the corresponding embryo and its implantation site. After washing in phosphate-buffered solution, pooled decidual tissues were cut into small pieces and digested three times with $1 \mathrm{mg} \mathrm{ml}^{-1}$ Dispase II (Roche, Basel, Switzerland) at $37^{\circ} \mathrm{C}$ for $20 \mathrm{~min}$ each cycle in a shaking water bath. When single or clumps of cells were observed under the microscope, the released cells were separated from undigested tissue pieces by filtering through a $40 \mu \mathrm{m}$ pore nylon mesh strainer (Thermo Fisher Scientific). MNCs were 


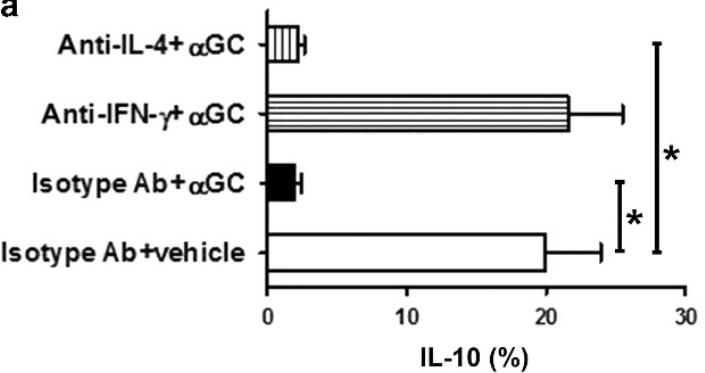

C

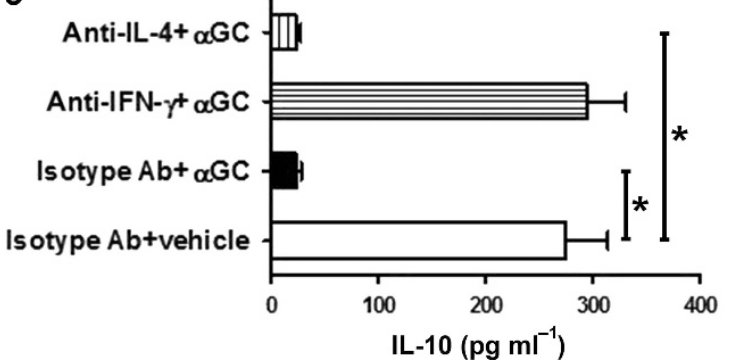

b

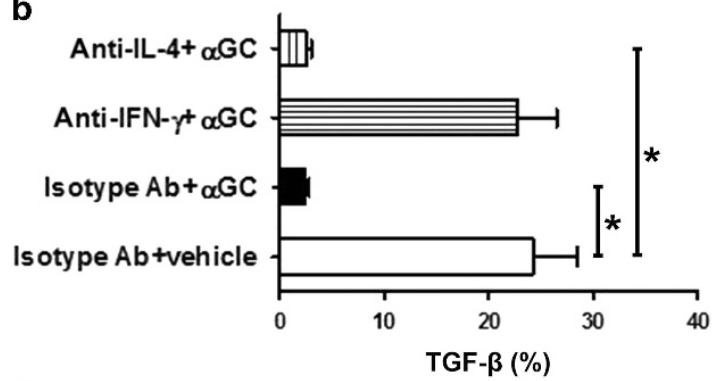

d

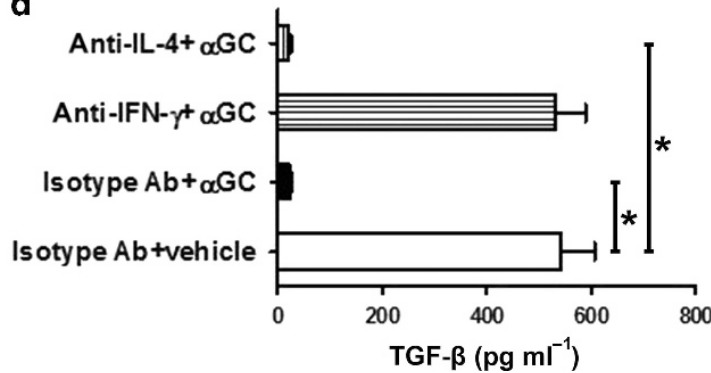

Figure 7 The invariant natural killer T (iNKT) cell-mediated decrease in the activation of decidual regulatory T (Treg) cells in vitro is interferon (IFN)- $\gamma$ dependent. Decidual iNKT cells from wild-type (c) mice were pretreated with antibodies (Abs) against IFN- $\gamma$, interleukin (IL)-4, or isotype control Ab $2 \mathrm{~h}$ before $\alpha$-galactosylceramide $\left(\alpha \mathrm{GC}\right.$ ) or vehicle treatment. A total of $5 \times 10^{4}$ decidual iNKT cells were co-cultured with $5 \times 10^{4}$ decidual Treg cells for $24 \mathrm{~h}$. The production of intracellular and extracellular IL-10 (a, c) and TGF- $\beta(\mathbf{b}, \mathbf{d})$ by decidual Treg cells were measured $(n=6)$. ${ }^{*} P<0.01$.

purified over a Ficoll-Paque Premium (GE Healthcare, Pittsburgh, PA, USA) by centrifugation at $400 \mathrm{~g}$ for $30 \mathrm{~min}$ at $20^{\circ} \mathrm{C}$.

Generation of iNKT cells. Isolation of iNKT cells has been described previously. ${ }^{53}$ Briefly, splenocytes or decidual MNCs were prepared and labeled with B220 microbeads (Miltenyi Biotec, Bergisch Gladbach, Germany). B cells were depleted from decidual MNCs using an autoMACS separator (Miltenyi Biotec). The B-cell-free fractions were then labeled with phycoerythrin (PE)-conjugated $\alpha$ GC-loaded CD1d tetramer (Miltenyi Biotec), washed and enriched for CD1d- $\alpha \mathrm{GC}$ tetramer ${ }^{+}$iNKT cells using anti-PE-microbeads (Miltenyi Biotec) and the autoMACS separator. The purity of sorted iNKT cells was defined as the percentage of CD1d- $\alpha \mathrm{GC}$ tetramer ${ }^{+} \mathrm{CD}^{+}$cells in the $\mathrm{CD}^{+}$ cell population and routinely exceeded $97 \%$, as determined using flow cytometry (data not shown).

Isolation of T-cell subsets. For adoptive transfer, Treg cells were isolated from the spleens of C57BL/6 mice on day 12.5 of gestation using a mouse $\mathrm{CD} 4{ }^{+} \mathrm{CD} 25^{+}$Treg cell isolation kit (Miltenyi Biotec) according to the manufacturer's instructions. For in vitro co-culture experiments, $\mathrm{CD} 4{ }^{+} \mathrm{CD} 25^{+}$Treg cells and CD $4{ }^{+} \mathrm{CD} 25^{-}$Tcon cells were sorted from the decidua of pregnant C57BL/6 mice. In brief, splenocytes or decidual MNC suspensions from C57BL/6 mice were prepared. The single-cell suspensions were then labeled with a biotin$\mathrm{Ab}$ cocktail, washed and incubated with anti-biotin microbeads and $\mathrm{CD} 25-\mathrm{PE} \mathrm{Ab}$. Non-CD4 ${ }^{+} \mathrm{T}$ cells were then magnetically depleted using the autoMACS separator. Unlabeled $\mathrm{CD}^{+}{ }^{+} \mathrm{T}$ cells were collected and incubated with anti-PE microbeads. $\mathrm{CD} 4{ }^{+} \mathrm{CD} 25^{+}$Treg cells and $\mathrm{CD} 4{ }^{+} \mathrm{CD} 25^{-}$Tcon cells were separately isolated using the autoMACS separator.

Cell co-culture. Isolated decidual iNKT cells $\left(2 \times 10^{5}\right.$ cells per ml $)$ from WT, $I F N-\gamma^{-1}$, or $I L-4^{-/}$mice were incubated with $\alpha \mathrm{GC}$ $\left(10 \mathrm{ng} \mathrm{ml}^{-1}\right)$ for $12 \mathrm{~h}$ and then extensively washed. Decidual iNKT cells treated with vehicle served as negative controls. In selected experiments, $\alpha \mathrm{GC}$-stimulated decidual iNKT cells from WT mice were pretreated with anti-IFN- $\gamma \mathrm{Ab}\left(10 \mu \mathrm{g} \mathrm{ml}^{-1}\right)$ (BioLegend), anti-IL-4 $\mathrm{Ab} \quad\left(10 \mu \mathrm{g} \mathrm{ml}^{-1}\right)$ (BioLegend), or isotype $\mathrm{Ab}\left(10 \mu \mathrm{g} \mathrm{ml}^{-1}\right)$
(BioLegend) $2 \mathrm{~h}$ before $\alpha \mathrm{GC}$ or vehicle treatment. A total of $5 \times 10^{4}$ decidual iNKT cells were co-cultured with $5 \times 10^{4}$ sorted decidual Treg cells in a 96 -well plate at $37^{\circ} \mathrm{C}$ in $5 \% \mathrm{CO}_{2}$ for $24 \mathrm{~h}$. Decidual Treg cell intracellular IL-10 and TGF- $\beta$ secretion was detected using flow cytometry. Supernatants were collected and analyzed for IL-10 and TGF- $\beta$ production using ELISA.

Treg cell suppressive activity analysis. One of the important functions of Treg cells is to suppress the proliferation and activation of effector lymphocytes. The suppressive activity of decidual Treg cells following $\alpha \mathrm{GC}$ injection was determined by measuring the proliferation of responder splenocytes co-cultured with decidual Treg cells. In brief, splenocytes were labeled with $1 \mu \mathrm{M}$ carboxyfluorescein diacetate succinimidyl ester (Molecular Probes, Eugene, OR, USA). Labeled splenocytes $\left(2 \times 10^{5}\right.$ cells $)$ were then cocultured with decidual Treg cells $\left(1 \times 10^{5}\right.$ cells $)$ from $\alpha$ GC-treated or vehicle-treated $\mathrm{C} 57 \mathrm{BL} / 6$ mice in the presence of $10 \mu \mathrm{g} \mathrm{ml}^{-1}$ concanavalin A (Sigma) in a 96-well plate for $72 \mathrm{~h}$. Proliferation of viable splenocytes (carboxyfluorescein diacetate succinimidyl ester dilution) was analyzed on a FACSCanto flow cytometer (BD Biosciences, San Jose, CA) using FlowJo software (Tree Star, Ashland, OR, USA).

The suppressive activity of decidual Treg cells was also investigated by assessing cytokine production by $\mathrm{CD} 4{ }^{+} \mathrm{CD} 25^{-}$Tcon cells cocultured with decidual Treg cells. ${ }^{54}$ Briefly, sorted decidual Tcon cells $\left(5 \times 10^{4}\right.$ cells $)$ were co-cultured with decidual Treg cells $\left(5 \times 10^{4}\right.$ cells $)$ from $\alpha$ GC-treated or vehicle-treated C57BL/6 mice with $50 \mathrm{ng} \mathrm{ml}^{-1}$ phorbol myristate acetate (Sigma) and $500 \mathrm{ng} \mathrm{ml}^{-1}$ ionomycin (Sigma) for $48 \mathrm{~h}$. Cell culture supernatants were analyzed for IFN$\gamma$ and TNF- $\alpha$ secretion using ELISA.

Flow cytometry. For iNKT cell analysis, cells were incubated with allophycocyanin (APC)/Cy7-conjugated anti-CD3 Ab $(0.25 \mu \mathrm{g})$ and PE-conjugated anti- $\alpha$ GC-loaded CD1d tetramer $\mathrm{Ab}(1 \mu \mathrm{g})$ for $30 \mathrm{~min}$ at $4{ }^{\circ} \mathrm{C}$. After washing twice with phosphate-buffered solution, cells were fixed in a fixation buffer. For intracellular cytokine staining, cells were resuspended in a permeabilization wash buffer and 
incubated with fluorescein isothiocyanate-conjugated anti-IFN- $\gamma \mathrm{Ab}$ $(1 \mu \mathrm{g})$ and APC-conjugated anti-IL-4 Ab $(1 \mu \mathrm{g})$. For Treg cell analysis, cells were incubated with fluorescein isothiocyanate-conjugated anti$\mathrm{CD} 4 \mathrm{Ab}(0.25 \mu \mathrm{g})$ for $30 \mathrm{~min}$ at $4{ }^{\circ} \mathrm{C}$. After washing twice with phosphate-buffered solution, cells were fixed in a fixation buffer. Cells were then resuspended in a permeabilization wash buffer and incubated with PE-conjugated anti-Foxp3 Ab $(1.0 \mu \mathrm{g})$, PE/Cy7conjugated anti-IL-10 $(0.25 \mu \mathrm{g})$, and APC-conjugated anti-TGF- $\beta$ $(0.5 \mu \mathrm{g})$ Abs. Isotype controls were established using matched fluorescence-labeled isotype control antibodies to account for nonspecific staining. Immunostained cells were analyzed on a FACSCanto flow cytometer using FlowJo software. The percentage of CD1d- $\alpha \mathrm{GC}$ tetramer ${ }^{+}$cells in the $\mathrm{CD}^{+}$cell population was measured. CD1d$\alpha \mathrm{GC}$ tetramer ${ }^{+} \mathrm{CD}^{+}$cells were gated and screened for intracellular IFN- $\gamma$ and IL- 4 production. The percentage of Foxp $3^{+}$cells in the $\mathrm{CD} 4{ }^{+}$cell population was assayed. Foxp $3^{+} \mathrm{CD} 4{ }^{+}$cells were gated and screened for intracellular IL-10 and TGF- $\beta$ production. Fluorescence-conjugated Abs, matched fluorescence-labeled isotype control Abs, permeabilization wash buffer, and fixation buffer were all purchased from BioLegend.

ELISA. Serums and cell culture supernatants were collected and stored at $-80^{\circ} \mathrm{C}$ for batched cytokine examination. The levels of IFN- $\gamma$, TNF- $\alpha$, IL-4, and IL-10 were assessed using commercially available ELISA kits (R\&D Systems, Minneapolis, MN, USA). All assays were conducted according to the manufacturer's instructions.

Statistical analysis. All statistical analyses were performed using SPSS 23.0 software (IBM, Armonk, NY, USA). For multiple group comparisons, data were analyzed using one-way analysis of variance with Bonferroni post-test when the variances were homogeneous or with Tamhane's T2 post-test when the variances were not homogeneous. Independent Student's $t$-test was used for comparisons between two groups. Results were expressed as mean \pm s.d. A $P$-value of $<0.05$ was considered significant.

\section{ACKNOWLEDGMENTS}

This work was supported by funding from the National Natural Science Foundation of China (81571510, 81370769 and 81200478) and the Guangzhou Science and Technology Plan Project (2014Y2-00202) to L.L.

\section{AUTHOR CONTRIBUTIONS}

L.L. and D.J.S. conceived and designed the study; J.T., Y.J., and J.Z. performed the experiments; L.L. performed the data analysis and wrote the draft manuscript; D.J.S. revised the manuscript. All authors contributed to the final version of the manuscript.

\section{DISCLOSURE}

The authors declared no conflict of interest.

c 2017 Society for Mucosal Immunology

\section{REFERENCES}

1. Girardi, G., Yarilin, D., Thurman, J.M., Holers, V.M. \& Salmon, J.E. Complement activation induces dysregulation of angiogenic factors and causes fetal rejection and growth restriction. J. Exp. Med. 203, 2165-2175 (2006).

2. Williams, Z. Inducing tolerance to pregnancy. N. Engl. J. Med. 367, 1159-1161 (2012).

3. Krieg, S. \& Westphal, L. Immune function and recurrent pregnancy loss. Semin. Reprod. Med. 33, 305-312 (2015).

4. Allanson, B. et al. Infection and fetal loss in the mid-second trimester of pregnancy. Aust. NZ J. Obstet. Gynaecol. 50, 221-225 (2010).

5. Srinivas, S.K. et al. Placental inflammation and viral infection are implicated in second trimester pregnancy loss. Am. J. Obstet. Gynecol. 195, 797-802 (2006).
6. Baud, D., Regan, L. \& Greub, G. Emerging role of Chlamydia and Chlamydia-like organisms in adverse pregnancy outcomes. Curr. Opin. Infect. Dis. 21, 70-76 (2008).

7. Boyson, J.E. et al. CD1d and invariant NKT cells at the human maternalfetal interface. Proc. Natl. Acad. Sci. USA 99, 13741-13746 (2002).

8. Ito, K. et al. Involvement of decidual V $\alpha 14$ NKT cells in abortion. Proc. Natl. Acad. Sci. USA 97, 740-744 (2000).

9. Kronenberg, M. \& Kinjo, Y. Innate-like recognition of microbes by invariant natural killer T cells. Curr. Opin. Immunol. 21, 391-396 (2009).

10. Pellicci, D.G. et al. Differential recognition of CD1d- $\alpha$-galactosyl ceramide by the V $\beta 8.2$ and $\mathrm{V} \beta 7$ semi-invariant NKT T-cell receptors. Immunity $\mathbf{3 1}$, 47-59 (2009).

11. Matsuda, J.L., Mallevaey, T., Scott-Browne, J. \& Gapin, L. CD1d-restricted iNKT cells, the 'Swiss-Army knife' of the immune system. Curr. Opin. Immunol. 20, 358-368 (2008).

12. Littman, D.R. \& Rudensky, A.Y. Th17 and regulatory T cells in mediating and restraining inflammation. Cell 140, 845-858 (2010).

13. Erlebacher, A. Mechanisms of $T$ cell tolerance towards the allogeneic fetus. Nat. Rev. Immunol. 13, 23-33 (2013).

14. Josefowicz, S.Z. et al. Extrathymically generated regulatory T cells control mucosal TH2 inflammation. Nature 482, 395-399 (2012).

15. Sakaguchi, S., Miyara, M., Costantino, C.M. \& Hafler, D.A. FOXP3 ${ }^{+}$ regulatory $T$ cells in the human immune system. Nat. Rev. Immunol. 10, 490-500 (2010).

16. Brunkow, M.E. et al. Disruption of a new forkhead/winged- helix protein, scurfin, results in the fatal lymphoproliferative disorder of the scurfy mouse. Nat. Genet. 27, 68-73 (2001).

17. Fontenot, J.D., Gavin, M.A. \& Rudensky, A.Y. Foxp3 programs the development and function of $\mathrm{CD} 4{ }^{+} \mathrm{CD} 25^{+}$regulatory $\mathrm{T}$ cells Nat. Immunol. 4, 330-336 (2003).

18. Teles, A. et al. Control of uterine microenvironment by foxp $3^{+}$cells facilitates embryo implantation. Front. Immunol. 4, 158 (2013).

19. Shima, T. et al. Regulatory T cells are necessary for implantation and maintenance of early pregnancy but not late pregnancy in allogeneic mice. J. Reprod. Immunol. 85, 121-129 (2010).

20. Nair, L.S. \& Nair, A.S. Effects of malaria infection on pregnancy. Indian J. Malariol. 30, 207-214 (1993).

21. Krishnan, L., Guilbert, L.J., Wegmann, T.G., Belosevic, M. \& Mosmann, T.R. Thelper 1 response against Leishmania major in pregnant C57BL/6 mice increases implantation failure and fetal resorptions. Correlation with increased IFN- $\gamma$ and TNF and reduced IL-10 production by placental cells. J. Immunol. 156, 653-662 (1996).

22. Kawano, T. et al. CD1d-restricted and TCR-mediated activation of $\mathrm{V} \alpha 14$ NKT cells by glycosylceramides. Science 278, 1626-1629 (1997).

23. Anderson, B.L., Teyton, L., Bendelac, A. \& Savage, P.B. Stimulation of natural killer T cells by glycolipids. Molecules 18, 15662-15688 (2013).

24. Yoshiga, Y. et al. Activation of natural killer T cells by $\alpha$-carba-GalCer (RCAl-56), a novel synthetic glycolipid ligand, suppresses murine collagen-induced arthritis. Clin. Exp. Immunol. 164, 236-247 (2011).

25. Taniguchi, M. et al. Essential requirement of an invariant $\mathrm{V} \alpha 14 \mathrm{~T}$ cell antigen receptor expression in the development of natural killer Tcells. Proc. Natl. Acad. Sci. USA 93, 11025-11028 (1996).

26. Rogers, L. et al. Deficiency of invariant $\mathrm{V} \alpha 14$ natural killer $T$ cells decreases atherosclerosis in LDL receptor null mice. Cardiovasc. Res. 78, 167-174 (2008).

27. Boyson, J.E., Nagarkatti, N., Nizam, L., Exley, M.A. \& Strominger, J.L. Gestation stage-dependent mechanisms of invariant natural killer T cellmediated pregnancy loss. Proc. Natl. Acad. Sci. USA 103, 4580-4585 (2006).

28. Li, Z.Y. et al. IFN- $\gamma$ modulates $L y-49$ receptors on NK cells in IFN- $\gamma$-induced pregnancy failure. Sci. Rep. 5, 18159 (2015).

29. Comba, C. et al. Role of inflammatory mediators in patients with recurrent pregnancy loss. Fertil. Steril. 104, 1467-1474.e1 (2015).

30. Wynn, T.A. Type 2 cytokines: mechanisms and therapeutic strategies Nat. Rev. Immunol. 15, 271-282 (2015).

31. Piccinni, M.P. T cell tolerance towards the fetal allograft. J. Reprod. Immunol. 85, 71-75 (2010).

32. Svensson, L., Arvola, M., Sällström, M.A., Holmdahl, R. \& Mattsson, R. The Th2 cytokines IL- 4 and $\mathrm{LL}-10$ are not crucial for the completion of allogeneic pregnancy in mice. J. Reprod. Immunol. 51, 3-7 (2001). 
33. Aluvihare, V.R., Kallikourdis, M. \& Betz, A.G. Regulatory T cells mediate maternal tolerance to the fetus. Nat. Immunol. 5, 266-271 (2004).

34. Mjösberg, J., Berg, G., Jenmalm, M.C. \& Ernerudh, J. FOXP3 ${ }^{+}$regulatory $T$ cells and $T$ helper $1, T$ helper 2 , and $T$ helper 17 cells in human early pregnancy decidua. Biol. Reprod. 82, 698-705 (2010).

35. Sharma, S. Natural killer cells and regulatory T cells in early pregnancy loss. Int. J. Dev. Biol. 58, 219-229 (2014).

36. Samstein, R.M., Josefowicz, S.Z., Arvey, A., Treuting, P.M. \& Rudensky, A.Y. Extrathymic generation of regulatory $T$ cells in placental mammals mitigates maternal-fetal conflict. Cell 150, 29-38 (2012).

37. Jin, L.P., Chen, Q.Y., Zhang, T., Guo, P.F. \& Li, D.J. The CD4 ${ }^{+} \mathrm{CD} 25^{\text {bright }}$ regulatory $T$ cells and CTLA-4 expression in peripheral and decidual lymphocytes are down-regulated in human miscarriage. Clin. Immunol. 133, 402-410 (2009).

38. Rowe, J.H., Ertelt, J.M., Xin, L. \& Way, S.S. Pregnancy imprints regulatory memory that sustains anergy to fetal antigen. Nature 490 , 102-106 (2012).

39. Zenclussen, A.C. et al. Abnormal T-cell reactivity against paternal antigens in spontaneous abortion: adoptive transfer of pregnancy-induced $\mathrm{CD} 4^{+}$ $\mathrm{CD}_{25}{ }^{+} \mathrm{T}$ regulatory cells prevents fetal rejection in a murine abortion model. Am. J. Pathol. 166, 811-822 (2005).

40. Gavin, M.A. et al. Single-cell analysis of normal and FOXP3-mutant human T cells: FOXP3 expression without regulatory T cell development. Proc. Natl. Acad. Sci. USA 103, 6659-6664 (2006).

41. Ito, T. et al. Two functional subsets of FOXP3 ${ }^{+}$regulatory Tcells in human thymus and periphery. Immunity 28, 870-880 (2008).

42. Roncarolo, M.G. et al. Interleukin-10-secreting type 1 regulatory T cells in rodents and humans. Immunol. Rev. 212, 28-50 (2006).

43. Andersson, J. et al. $\mathrm{CD}^{+}{ }^{+} \mathrm{FoxP}^{+}$regulatory $\mathrm{T}$ cells confer infectious tolerance in a TGF- $\beta$-dependent manner. J. Exp. Med. 205, 1975-1981 (2008).
44. Sakaguchi, S., Sakaguchi, N., Asano, M., Itoh, M. \& Toda, M. Immunologic self-tolerance maintained by activated T cells expressing IL-2 receptor alpha-chains (CD25). Breakdown of a single mechanism of self-tolerance causes various autoimmune diseases. J. Immunol. 155, 1151-1164 (1995).

45. Murphy, S.P. et al. Evidence for participation of uterine natural killer cells in the mechanisms responsible for spontaneous preterm labor and delivery. Am. J. Obstet. Gynecol. 200, 308.e1-9 (2009).

46. Gomez-Lopez, N., StLouis, D., Lehr, M.A., Sanchez-Rodriguez, E.N. \& Arenas-Hernandez, M. Immune cells in term and preterm labor. Cell. Mol. Immunol. 11, 571-581 (2014).

47. Paget, C. \& Trottein, F. Role of type 1 natural killer T cells in pulmonary immunity. Mucosal Immunol. 6, 1054-1067 (2013).

48. Li, L. et al. Role of invariant NKT cells in lipopolysaccharide-induced pregnancy loss. Cell. Immunol. 286, 1-10 (2013).

49. Nagarajan, N.A. \& Kronenberg, M. Invariant NKT cells amplify the innate immune response to lipopolysaccharide. J. Immunol. 178, 2706-2713 (2007).

50. Cui, J. et al. Requirement for $\mathrm{V} \alpha$ NKT cells in IL-12-mediated rejection of tumors. Science 278, 1623-1626 (1997).

51. Wang, S., Li, C., Kawamura, H., Watanabe, H. \& Abo, T. Unique sensitivity to $\alpha$-galactosylceramide of NKT cells in the uterus. Cell. Immunol. 215, 98-105 (2002).

52. Leber, A., Teles, A. \& Zenclussen, A.C. Regulatory T cells and their role in pregnancy. Am. J. Reprod. Immunol. 63, 445-459 (2010).

53. Li, L., Yang, J., Jiang, Y., Tu, J. \& Schust, D.J. Activation of decidual invariant natural killer Tcells promotes lipopolysaccharide-induced preterm birth. Mol. Hum. Reprod. 21, 369-381 (2015).

54. Hongo, D., Tang, X., Dutt, S., Nador, R.G. \& Strober, S. Interactions between NKT cells and Tregs are required for tolerance to combined bone marrow and organ transplants. Blood 119, 1581-1589 (2012). 